\title{
Community Interpreting: signed or spoken? Types, modes, and methods
}

\author{
Nadja Grbić \& Sonja Pöllabauer \\ University of Graz
}

This article focuses on the similarities and differences between spoken and signed language Community Interpreting (CI). After a brief overview of the various terms that are generally used in the relevant literature - albeit inconsistently - to categorize various sorts of interpreting (type, mode, setting), we examine a number of typologies of interpreting events that have been developed in order to allow for a more complex categorization of such events. A brief outline of the history of research into spoken and signed language CI is complemented by a short description of the similarities and differences between spoken and signed language CI. We also discuss various examples of research methods that have been applied to spoken and signed language $C I$.

\section{Modes, types and settings}

Terms such as mode, type, and setting are commonly used in writings about interpreting. Labels such as these allow us to define our subject area and differentiate between various categories. Despite the fact that these terms seem to occupy a central position in interpreting studies (IS), they tend to be used in a fairly inconsistent manner. A cursory comparison of entries in general translation studies (TS) resource books, e.g. the Dictionary of Translation Studies (Shuttleworth \& Cowie 1997), the Routledge Encyclopedia of Translation Studies (Baker 1998), and the Handbuch Translation (Snell-Hornby et al. 1998) serves to corroborate this assumption.

All of these reference sources make a distinction between interpreting mode and type. The use of mode or type is, however, by no means consistent: with regard to the "way in which it is carried out" (Shuttleworth \& Cowie 1997: 84) English reference books use practice (Shuttleworth \& Cowie 1997: 142), form (ibid.: 197) and type (Shuttleworth \& Cowie 1997: 93) in addition to mode. In German sources, we find terms such as Erscheinungsform ("manifestation"), Art ("type"), Form ("form") (cf. Pöchhacker 1998a: 301), and Dolmetschtechnik ("interpreting technique") (Grünberg 1998: 317).

For the "context in which it occurs" (Shuttleworth \& Cowie 1997: 84), English literature uses form (ibid.: 23) in addition to type (Gile 1998: 40). German sources also use Erscheinungsform ("manifestation") (SnellHornby et al. 1998) and Sonderform ("special form") (Kurz 1998: 311). Terms such as mode and type seem to be those most commonly used and will therefore be treated as the main distinctions for the purposes of this ar- 
ticle. The following types and modes have been examined in (separate) articles in the three translation reference resources mentioned above.

Table 1: Articles on various types and modes.

\begin{tabular}{|l|c|c|c|}
\hline & $\begin{array}{c}\text { Shuttleworth \& Cowie } \\
1997\end{array}$ & $\begin{array}{c}\text { Baker } \\
1998\end{array}$ & $\begin{array}{c}\text { Snell-Hornby et al. } \\
1998\end{array}$ \\
\hline $\begin{array}{l}\text { Consecutive Interpreting } \\
\text { (Konsekutivdolmetschen })\end{array}$ & Article & - & Article \\
\hline $\begin{array}{l}\text { Simultaneous Interpreting } \\
\text { (Simultandolmetschen) }\end{array}$ & Article & $\begin{array}{c}\text { Joint de- } \\
\text { scription }\end{array}$ & Article \\
\hline Whispered Interpreting & Article & - & - \\
\hline Sight Interpreting/translation & Article & - & - \\
\hline Relay Interpreting & Article & - & Article \\
\hline $\begin{array}{l}\text { Conference Interpreting (Kon- } \\
\text { ferenzdolmetschen) }\end{array}$ & Article & $\begin{array}{l}\text { Joint de- } \\
\text { scription }\end{array}$ & Article \\
\hline $\begin{array}{l}\text { Court Interpreting (Gerichts- } \\
\text { dolmetschen) }\end{array}$ & Article & Article & Article \\
\hline $\begin{array}{l}\text { Community Interpreting } \\
\text { (Community Int.) }\end{array}$ & Article & Article & Article \\
\hline $\begin{array}{l}\text { Media Interpreting } \\
\text { (Mediendolmetschen) }\end{array}$ & - & - & Article \\
\hline $\begin{array}{l}\text { Signed Language (SL) Inter- } \\
\text { preting (Gebärdensprachdol- } \\
\text { metschen) }\end{array}$ & Article & Article & Article \\
\hline $\begin{array}{l}\text { Liaison Interpreting (Verhand- } \\
\text { lungsdolmetschen) }\end{array}$ & Article & - & Article \\
\hline $\begin{array}{l}\text { Remote conference Interpret- } \\
\text { ing (Satelliten-Konferenzdol- } \\
\text { metschen) }\end{array}$ & - & - & \\
\hline
\end{tabular}

A survey of these resources shows not only that the terminology is used inconsistently, but also that different articles describe different types and modes. CI and signed language interpreting are treated as distinct entities and are referred to in separate articles in these publications.

The traditional distinction between consecutive and simultaneous as the two main interpreting modes has been in common use since the development of the simultaneous interpreting technique in the first half of the twentieth century. The categorization of interpreting according to interpreting type, i.e. the social context in which the interpreting assignment is carried out, is also widely applied, although the application of type is less consistent than that of mode.

The term setting is also ambiguous. Setting is often used, both in English and in German (as a loanword) to refer to the place in which the interpreting event happens (e.g. a hospital, a police station) (cf. Humphrey \& Alcorn 1995: 291-340; Gentile 1997: 111). (Gentile also further subdivides settings into "quasi-speciali[z]ed fields" such as mental health, oncology, and speech therapy for the medical setting). Setting, however, is sometimes also used as a synonym for a specific sub-type of interpreting, such as medical or legal interpreting (cf. e.g. Roberts 1997: 9; Shuttleworth \& Cowie 1997: 23). In some publications, settings are also referred to as situations (Gentile et al. 1996: 18), contexts (Gentile 1997: 111f.) or areas (ibid.: 111; Wadensjö 1998a: 33). Pöchhacker (2004: 13f.), for instance, also uses set- 
ting to differentiate between intersocial and intrasocial contexts of interaction.

\section{Typologies}

For heuristic reasons, several attempts have been made to establish more complex and comprehensive categorizations of interpreting events. A number of authors, for example, have drawn up lists of classification criteria (mainly) in order to distinguish CI from conference interpreting; they do not, however, intend to present an exhaustive typology covering all types of interpreter-mediated events (e.g. Gentile et al. 1996: 18).

Others, such as Mason (1999: 148f.), employ a more systematic approach. He uses the variables mode (consecutive, simultaneous, etc.), field (medical, courtroom, etc.) and tenor (addresser/addressee relationships) and bases his model on Halliday's systemic functional language theory. Both Mason and Gentile take spoken and signed language interpreting into account. Authors such as Alexieva $(1997)^{3}$ or Pöchhacker $(2000,2004)$ have developed even more complex and elaborate typologies.

Alexieva (1997) developed a multi-parameter typology based on prototype theory according to which she proposes two sets of criteria: mode of delivery (simultaneous, consecutive, chuchotage or whispered interpreting, and liaison), and elements of the communicative situation (primary and secondary participants, number of participants, command of language, status, topic, type of text, etc.). Some of these criteria are discussed in terms of their degree of (cultural) embeddedness on a scale ranging between universality and culture-specificity. Although Alexieva's typology does include $\mathrm{CI}$, there are limits with regard to its application to the field of signed language interpreting. In the context of her exclusive concern with the modality of spoken language, the typology cannot in fact be applied to sign languages at all. Mason (1999: 148), on the other hand, makes explicit reference to signing in his work.

Pöchhacker's map of the territory of IS, which illustrates the broad spectrum of research into IS, first came out in 2000 and was published again with slight changes in 2004. It is a 'spectral model' of interpreting research based on Snell-Hornby's prototypology of the spectrum of translation phenomena, which strives to avoid clear-cut, static categories and instead allows for fuzzy edges between variable factors.

The spectral model introduces a set of eight 'vertical dimensions': medium, setting, mode, languages (cultures), discourse, participants, interpreter, and problem. Each of these comprises several 'horizontal parameters'. The setting dimension of the spectrum, for example, comprises both international and intrasocial settings at multilateral conferences on the lefthand side, media interpreting in the middle and interpreting in health or social settings on the far right. In the 2000 version, the spectrum is complemented by a "three worlds" model ("3-Welten-Schema") of IS (cf. Pöch- 
hacker 2000: 124), where the geopolitical metaphors of 'first' and 'third' world are used to describe the 'IS world'. Conference interpreting is located in the first world, CI in the third world and signed language interpreting appears both in the third world and in the middle of the spectrum.

In order to avoid grading interpreting events (i.e. positioning some at the centre and others at the periphery), Turner \& Pollitt (2002: 41) proposed the notion of "hybrid" forms of interpreting, which could open up "the possibility of revisiting our understanding of other forms and [permit] some of their richly textured hybridity to be appreciated and more fully understood".

\section{Community Interpreting research: signed vs spoken}

The need for a better and (fairer) provision of language services for immigrants and minority groups has triggered a trend towards research into interpreting in community-based settings (cf. Gile 2004: 20). Research on CI has gradually earned its way into IS and become an accepted field of research - although this was not always the case.

In 1998, for example, Pöchhacker still had to argue that "[ $t]$ here is more to interpreting" (1998b: 172) than conference interpreting and call for an "opening up within and across" (ibid.: 175) the discipline even though the term "community interpreting" had already been employed in general reference resources on TS (see above). Four years later, the Interpreting Studies Reader (Pöchhacker \& Shlesinger 2002) included seminal works on CI and in 2004, Introducing Interpreting Studies (Pöchhacker 2004), the first comprehensive textbook in the field of IS, undisputedly included CI in a conceptual " "map' of the territory of interpreting studies" (ibid.: 23f.).

The first publications on CI date back to the 1980s (or even as far back as the 1970s). Many of these early publications are non-academic handbooks or 'guidelines' for interpreters in community-based settings, and/or service-providers, often mirroring the authors' personal experiences.

It was only in the early 1990s that CI became the focus of stringent scientific studies based on theory. Berk-Seligson's investigation into court interpreting (1990) and Wadensjö's (1992) examination of interpreting in immigration hearings and medical encounters are often referred to as the vanguard of this new 'domain' of interpreting research (IR) (cf. Pöchhacker \& Shlesinger 2002: 7).

Up to now, we have only referred to 'interpreting' and CI in general terms in this section. If we take a brief look at the history of research into signed language interpreting, it soon becomes evident that research into spoken and signed language interpreting have for a long time been parallel endeavours, without any systematic reciprocal reception. Of the three articles on CI in the reference books mentioned above, only Wadensjö (1998a: 34 ), for example, refers to signed language interpreting, and even then only in conjunction with training. The articles on signed language interpreting, on the other hand, all refer to CI. 
Writings on signed language interpreting were first published in the mid-1960s, following the founding of the Registry of Interpreters for the Deaf (RID) in the USA in 1965. As a result, issues of professionalization and training were thrust into the limelight. In a situation analogous to that in the realm of spoken CI, many of the early publications on signed language interpreting mirrored the authors' personal views, rather than being based on research.

A "milestone event" (Pöchhacker 2004: 34) in IS, the 1977 NATO conference in Venice, brought researchers from various disciplines together with practising interpreters, including SL researchers and interpreters. In the conference proceedings, Ingram (1978: 109) pointed out that "the interpretation of sign languages is an integral part of the general study of interpretation and that no description [...] of interpretation which fails to take account of sign language interpretation can be regarded as complete".

This first advance towards signed language interpreting did not, however, last very long. Signed language interpreting did not appear on the agenda of subsequent IS conferences, and publications on signed language interpreting did not start to appear in 'mainstream' IS journals or researchoriented conference proceedings until the 1990s. A handful of papers, however, were published in the proceedings of the more practice-oriented annual conferences of the American Translators Association (ATA) in the 1980s.

Empirical research into signed language interpreting nonetheless started earlier than research into spoken language CI. Seven (unpublished) doctoral dissertations were defended as early as the 1970s, most of them exploring the effects of interpreter output, predominantly in educational settings. The 1980s saw the publication of two textbooks (Neumann Solow 1981; Frishberg 1986 ${ }^{4}$ ) and in 1985, the RID launched the Journal of Interpretation and also regularly published the proceedings of the national conventions of the RID, starting in the early 1970s. Still, monographs representing more comprehensive empirical studies rooted in theory (often based on sociolinguistics) did not start to appear until the 1990s, as can be seen in the publication of Cokely's pioneering book in 1992.

Today, alongside research into spoken language CI, signed language interpreting is an integral branch of IS. The series of Critical Link Conferences, launched in $1995^{5}$, which bring spoken and signed language interpreters and researchers together, provided a vital impulse for an increase in contact between the two branches. 


\section{Similarities and differences: signed vs spoken}

Signed language interpreting is neither an interpreting mode nor an interpreting type (see above), whereas CI can be seen as a type, subsuming a range of different sub-types or settings. Any attempt to define signed language interpreting as a separate category is useful only for pragmatic reasons, helping to structure research, for example, in order to catalogue publications in bibliographies.

Ozolins \& Bridge (1999) ${ }^{6}$ illustrate several differences between spoken and signed language interpreting. We would like to take these as a starting point for a discussion of further dimensions and aspects. We do not, however, attempt to present an exhaustive typology of parameters here.

In most countries, spoken and signed language interpreting have developed as distinct spheres (cf. ibid.: 19). One of the consequences of this lack of contact between the two branches is that conference, community and signed language interpreters are usually trained at different institutions without much mutual exchange. This lack of contact and exchange is also evident in research into spoken and signed language interpreting.

With regard to types and settings, signed language interpreting can take place in typical community settings (e.g. medical, social, legal), but is also used in conference and media settings and in settings that are not quite as common for spoken language community interpreters (e.g. classroom interpreting, religious contexts, meetings between deaf groups and government bodies, political campaigns, spa treatment programmes, staff meetings, and various kinds of 'show' interpreting carried out for PR purposes, even if there are no deaf people in the audience).

Ozolins \& Bridge (1999: 21) were the first to mention one vital distinction between spoken and signed language interpreting: the fact that signed language interpreting is never "terminal" - which is to say that deaf people will always need interpreters, whereas clients of spoken language CI may eventually learn the host country's language(s).

Spoken and signed language interpreting also differ with regard to the interpreting mode. CI in spoken languages is usually conducted in the consecutive mode (with short turns and very often without note-taking) - as opposed to simultaneous or consecutive modes in conference or workshop settings. Although chuchotage could also be used, in practice it is only rarely employed for spoken language CI, mainly as a result of the lack of training of many community interpreters. Signed language interpreting could, in principle, always use simultaneous interpreting, as two different modalities (visual-spatial and auditory-vocal) are involved, although some practitioners and researchers call for an increased use of the consecutive mode (cf., for instance, Russell 2005).

Ozolins \& Bridge (1999: 21) also note that signed language interpreting plays a significant role in the standardization (and, we would like to add, in the overall use) of SLs, as interpreters themselves have a major influence on the use of SL, for instance in classroom interpreting, where deaf students can be seen to emulate the interpreters' use of SL. Interpreters 
might, for instance, introduce new signs to denote special vocabulary, and they can choose to interpret either into a natural SL or into vernacular-based sign systems (i.e. interpreting versus transliteration), or to use a mixed variety.

As for the languages involved, it is important to note that signed language interpreting includes not only bilingual but also bimodal interpreting. It is inherent in the nature of SLs as visual-spatial languages that information is produced 'differently': SLs require a more visual encoding of information than spoken languages. SL interpreters therefore require particularly detailed and explicit information in the spoken language, for example with regard to visual or temporal aspects, in order to be able to interpret the meaning adequately into a SL (cf. Brennan \& Brown 1997). However, there are also situations in spoken languages where the original information has to be made more explicit in the interpretation than it was in the original. The word 'mountain', for example, could refer to 'alpine mountain ranges' but also to smaller elevations ('hills'), depending on the speaker's personal perspective. There are situations (e.g. police hearings) where the inadequate explanation of such terms could lead to grave misunderstandings or potentially even to the allegation that the suspect or person questioned is lying.

Last but not least, there is a distinction between spoken and signed language CI that is inherent in nature: that is, the fact that spatial and physical factors (seating, lighting requirements, etc.) play an important role in the realm of signed language interpreting. It is furthermore worth mentioning the long-running general assertion that deaf people would never be able to work as interpreters (as opposed to migrants in the realm of spoken CI, who could). Today, however, we see the emergence of deaf interpreters as a new and distinct group of professionals in the interpreting field, working for example as relay interpreters and translators ${ }^{7}$ (cf. e.g. Boudreault 2005; Forestal 2005a).

It is furthermore worth noting that in the context of spoken language CI the interpreters themselves often (but not always) share their clients' ethnic, linguistic or cultural backgrounds. In the context of signed language interpreting, on the other hand, the introduction of formal signed language interpreting training programmes has led to a general change, meaning that there are fewer children of deaf adults (CODAs) working as (untrained) interpreters today. Moreover, it is clear that SL interpreters, including CODAs, will never entirely 'belong to' or be a part of the deaf community insofar as they are able to hear (cf. Napier 2002: 29). When interpreters do not have the same linguistic or ethnic background as their (migrant) clients in the context of spoken CI, they sometimes employ a lingua franca. This can result not only in linguistic problems but can also carry a strong and inherent ideological dimension with regard to language rights and linguistic equality.

Both spoken and SL interpreters have to deal with (emotional) stress and assignments in the course of which they are not given adequate time to rest. Team interpreting, which can allow for longer periods of rest for indi- 
vidual interpreters, is not as common in the realm of spoken and signed language $\mathrm{CI}$ as it is, for example, in spoken language conference interpreting we would even go so far as to assert that team interpreting is practically non-existent in spoken language CI. Besides, SL interpreters are subject to an additional occupational syndrome exclusive to their work: the occupational overuse syndrome, which can develop as a result of constant strain and the overuse of specific muscles, tendons, and other soft tissues (cf. Madden 2005).

As we have illustrated above, there are several differences between spoken and signed language CI. There are also, however, a number of characteristics that pertain to spoken and signed language CI alike. CI situations, for instance, generally involve face-to-face dialogue, often with long stretches of largely unplanned discourse (as opposed to monologic, scripted texts at conferences). Dialogic talk also often involves shorter turns, which have to be interpreted in both language directions (bidirectionality as opposed to unidirectionality in conference settings). The style and register of the interpreted material can vary on a scale ranging from (very) formal to (very) informal. The speakers' linguistic proficiency might also differ greatly, and one often encounters a lack of knowledge about the respective speaker's culture and culturally determined behaviour (e.g. face-saving and politeness strategies, nonverbal behaviour), or differing styles of communication (e.g. turn-taking, pauses, gaze behaviour). CI situations are often characterized by an asymmetry of power and discourse control and by unequal access to (mainstream) services. One of the clients in an interpreting situation (i.e. for example a migrant or deaf client) usually occupies a lower status in the majority culture, whereas the other client may often be seen as a 'gate-keeper' who has the right to grant or refuse access to public services. The interpreted languages are often considered to be languages of a lower status (e.g. languages of limited diffusion, LLDs, pidginized variants or SLs). Spoken and signed language interpreters in community settings are often 'lay' interpreters, with a lack of proper training (although the training situation for signed language interpreting has improved considerably over time). They cannot 'hide' in the interpreting booth and are highly visible in interpreting situations, which often focus on personal and sometimes (but not always) highly intimate and emotional topics. As a result of their visibility, they no longer function as mere language 'conduits' but often have to assume a more active role, which also includes establishing strategies to coordinate the conversation and explaining culturally determined behaviour. For both spoken and signed language interpreters, these situations may sometimes lead to ethical dilemmas and personal conflicts with regard to their role in the exchange.

Humphrey \& Alcorn (1995: 156-158) put together a table of signed language interpreting events, taking the number of clients in interpreted interactions as the basic variable. For each area of work (education, religious, mental health, etc.), they distinguish between three types of interaction: one-on-one, small group, and large group. In the medical 'area of work', for example, we find one-on-one medical consultations with the patient, small 
group meetings with family or staff and large group sessions for community health programmes in larger rooms, such as a big auditorium.

\section{Research Methods}

In this section we focus on methods of research into spoken and signed language CI and provide examples of different (methodological) approaches. The scarcity of publications focusing on both spoken and signed language interpreting hardly comes as a surprise. Although some authors do refer to the literature of the respective 'other' modality, empirical data concentrate almost exclusively on either spoken or signed language interpreting (with the exception of for example Shaw et al. 2004, although the work does not address the topic of CI).

Given the limited scope of this article, we cannot provide a comprehensive (quantitative) analysis of the relevant literature. Instead, we provide an overview of examples of easily accessible publications. We have not included court interpreting in this overview. (For a discussion of the blurred distinctions between CI and court interpreting, cf. Berk-Seligson 2000).

Research can generally be divided into the categories of mainly theoretical or mainly empirical publications, or works that combine both theoretical 'ideas' and empirical data. In studies on CI, we find theoretical, empirical and 'combined' approaches. If, however, we were to exclude the wealth of non-scientific, anecdotal publications on CI, which abound in the literature, we would hardly find any publications that could be regarded as strictly theoretical. There are also numerous 'compilatory' papers in which aspects of CI are discussed on the basis of literature pertaining to the topic. One exception amongst authors working on spoken language CI is, for example, Inghilleri (2003 et passim), who strives to develop a theoretical framework for the analysis of interpreter-mediated discourse (in immigration settings) based on Bourdieu, Bernstein and the concept of translational norms of Descriptive Translation Studies (DTS).

The vast majority of publications on CI comprise a (more or less comprehensive) theoretical introduction, which is then complemented by empirical data. The theoretical 'framework' of publications on CI is often based on writings pertaining to other (related) disciplines (e.g. (socio)linguistics, sociology, psychology, cultural anthropology) or - to a lesser degree - approaches in TS proper (e.g. DTS, functional approaches). Wadensjö's pioneering monograph (1992, republished in 1998) on spoken CI in immigration and health settings is an example of an interdisciplinary theoretical approach. Metzger (1999) provides us with an example of an interdisciplinary approach with regard to signed language interpreting.

Pöchhacker's study (2000) on CI in Austrian health settings includes aspects of DTS and functionalist translation theory - an approach he refers to as "functionalist descriptivism" (2000: 289). Functionalist translation theory has been used as a framework for work on signed language interpret- 
ing too, although predominantly in the context of (community) translation (cf. Tate et al. 2003) or non-community settings, such as theatre interpreting.

Research can furthermore be classified as (mainly) deductive, i.e. a research hypothesis or 'theory' is developed on the basis of a theoretical framework and then tested against empirical data, or inductive, i.e. certain phenomena are observed, data on these phenomena are collected and an explanatory theory is then formulated on the basis of recurrent patterns in these data. These concepts, however, are neither mutually exclusive, nor are the boundaries between them entirely clear-cut, as many research methods involve both inductive and deductive elements. All of the examples mentioned in this section are based on a primarily deductive approach.

Empirical studies can be quantitative or qualitative, or use a combination of quantitative and qualitative methods of evaluation, as we will go on to discuss. Quantitative methods focus on measurable, 'quantifiable' categories in larger samples (very often based on statistics) and include, for example, large-scale, structured surveys based on questionnaires. Qualitative methods strive to describe and interpret a number of different (interrelated) variables in smaller corpora and include, for example, participant observation (overt or covert), interviews (open interviews, focus-group interviews), the collection and analysis of (authentic or simulated) texts, documents or recorded data (e.g. audio or video recordings of interpreter-mediated interactions) and transcripts of such interactions.

Qualitative empirical studies may use primary data, i.e. data collected by the researchers themselves (or third parties), or secondary data, i.e. they (re)analyse already existing data, such as statistics, newspaper reports, official records, etc.

In the context of $\mathrm{CI}$, we find a number of (usually questionnairebased) quantitative studies based on primary data. In his work on CI, Pöchhacker (2000), for instance, used a questionnaire to conduct a large-scale survey on service providers' expectations in Viennese hospitals. Mesa (2000) carried out another large-scale survey on spoken CI and users' and interpreters' expectations and views on the standards of interpreting. Forestal (2005b) conducted a large-scale survey on deaf leaders' attitudes towards signed language interpreting, and Grbić (2006) conducted a comprehensive empirical study on the nature of SL interpreters' assignments in the region of Styria, Austria, analysing questionnaires for every single interpreting session that took place over a two-year period.

In addition to such large-scale studies, we encounter a plethora of smaller questionnaire-based surveys - often categorized as 'pilot studies' that are not always strictly quantitative, or reports on training programmes or interpreter services. For the sake of brevity, though, we cannot provide an exhaustive overview of such publications in this article.

A considerable number of empirical studies on spoken and signed language CI are corpus-based discourse analytical studies (often case studies involving participant observation) that focus on various different aspects (e.g. role, face, politeness, 'errors', quality, terminology.) of interpreter-me- 
diated discourse ${ }^{8}$. These studies use a range of different discourse analytical approaches (e.g. (socio)linguistics, sociological, anthropological) and often - though not always (see below) - focus on authentic ('primary') data (e.g. Wadensjö 1992/1998b; Barsky 1994, Meyer 2004 on spoken CI, and Metzger 1999 and Roy 2000 on signed language interpreting). The sizes of the corpora in spoken CI vary greatly and range from corpora with one or two brief recordings (e.g. Englund Dimitrova 1997) to larger corpora with several hours of recordings (e.g. Pöllabauer 2005). Corpora used in research on signed language interpreting tend to be smaller, as the transcription of SLs is extremely laborious as a result of their complexity of articulation and unwritten nature. Sanheim (2003), for instance, used a medical interview from an earlier study by Metzger (1999) for her analysis of turn exchanges.

A smaller number of studies also use secondary data to investigate issues of CI. Berk-Seligson (2000), for instance, analysed the records of appeal cases from police interviews, and Barsky (1994) includes official transcripts of asylum hearings in his analysis.

With regard to empirical data and research methods, we can also differentiate between observational research and experimental research (cf. Gile 1998). Up to now, we have mainly referred to observational data collected in 'case studies', i.e. 'naturally occurring' data, as opposed to 'artificially created' data, which can be gleaned from 'experiments'. Experimental research is fairly prominent in the context of conference IR, but has been less common in research on CI to date. One often-cited example of experimental research design in IR is Berk-Seligson's (1990) study on politeness in court interpreting. Fowler (2003) conducted a small experiment on record-taking in police hearings. Other studies on CI that could best be classified as 'experimental' research include research projects using simulated non-authentic data, such as, for instance, staged role-plays (e.g. Cokely 1982; Cambridge 1999 on information loss in signed resp. spoken medical settings). Metzger (1999) based her study on a combination of authentic and simulated data from interpreter education programmes.

In addition to the methods of empirical social research we have mentioned up to now, we also find studies of IR and CI research which employ (quantitative) methods of psychology such as personality studies. One of the best examples of the few works that have used (and adapted) a psychological test (Ethnocentrism Scale) to study interpreters' perceptions of their role(s) was conducted by Angelelli (2004). Seal (2004) conducted a series of psychological tests with SL interpreters, where, among other results, a comparison between the responses of educational and community interpreters revealed no differences.

As mentioned above, many studies combine both qualitative and quantitative methods or make use of different qualitative methods (often referred to as a 'triangulation' of methods - for a discussion of the term cf. Hansen 2005). This triangulation of methods can be found in several studies on spoken CI, such as Pöchhacker (2000), where he discusses data gleaned from a questionnaire-based survey but also analyses authentic recordings 
from a descriptive viewpoint. A combination of various qualitative methods (discourse analysis, analysis of secondary data) can be found in Barsky (1994). Madden (2005) uses both quantitative and qualitative methods (a questionnaire-based survey and interviews) in her study on occupational overuse syndrome among SL interpreters in Australia. A combination of qualitative and quantitative methods as well as observation and analysis of authentic data has also been used in a large-scale project on deaf people's access to justice in the UK (Brennan \& Brown 1997).

The replication of existing studies is an important factor not only in order to compare and contrast data but also in terms of what might be described as "representativeness", as replication generates new data and can therefore serve to "increase" overall sample size (Gile 1998: 83). There are, however, only very few examples of such work, such as Sanheim's (2003) analysis of turn exchanges, which is a replication of Roy's study (2000) based on data collected by Metzger (1999).

\section{Conclusion}

After a brief overview of the terminological use of the expressions mode, type, and setting, we presented a comparison of the similarities and differences between the realms of spoken and signed language CI and research conducted in the field. A brief discussion of a number of CI studies based on a range of different approaches and methods showed that there is a wealth of publications on both spoken and signed language CI in a variety of settings. The fact that existing bodies of knowledge have been gradually integrated into research and that the divide between spoken and signed language interpreting research has been partially overcome, is certainly a step in the right direction. Today, publications on both modalities of interpreting often refer to literature pertaining to the respective 'other' modality. It is nonetheless evident that there is a continuing lack of empirical studies that focus on spoken and signed language interpreting as a common field, examining the two forms from a single perspective. It would therefore be desirable that the similarities and differences that have been discussed only on the basis of literature or personal experience to date can now be taken as the foundation for new studies, combining and contrasting these sources with empirical data.

\section{Bibliography}

Alexieva, Bistra (1997). “A Typology of Interpreter-Mediated Events”. The Translator 3(2), 153174.

Angelelli, Claudia (2004). Revisiting the Interpreter's Role. Amsterdam/Philadelphia: John Benjamins.

Baker, Mona (ed.) (1998). Encyclopedia of Translation Studies. London/New York: Routledge.

Barsky, Robert F. (1994). Constructing a Productive Other. Discourse Theory and the Convention Refugee Hearing. Pragmatics \& Beyond Series 29. Amsterdam/Philadelphia: John Benjamins. 
Berk-Seligson, Susan (1990). The Bilingual Courtroom. Court Interpreters in the Judicial Process. Chicago/London: University of Chicago Press.

Berk-Seligson, Susan (2000). "Interpreting for the police: Issues in the pre-trial phases of the judicial process". Forensic Linguistics: The International Journal of Speech, Language and the Law 7(1), 213-238.

Boudreault, Patrick (2005). "Deaf Interpreters“. Janzen (2005), 323-355.

Brennan, Mary \& Richard Brown (1997). Equality before the law. Deaf people's access to justice. Durham: Deaf Studies Research Unit.

Cambridge, Jan (1999). "Information Loss in Bilingual Medical Interviews through an Untrained Interpreter". The Translator 5(2), 201-219.

Carr, Silvana E., Roda Roberts, Aideen Dufour \& Dini Steyn (eds) (1997). The Critical Link: Interpreters in the community. Papers from the $1^{\text {st }}$ International Conference on Interpreting in Legal, Health, and Social Service Settings, Geneva Park, Canada, June 1-4, 1995. Amsterdam/Philadelphia: John Benjamins.

Cokely, Dennis (1982). "The interpreted medical interview: it loses something in the translation". The Reflector 3, 5-10.

Cokely, Dennis (1992). Interpretation: A Sociolinguistic Model. Burtonsville, MD: Linstok Press.

Englund Dimitrova, Birgitta (1997). "Degree of Interpreter Responsibility in the Interaction Process in Community Interpreting". Carr et al. (1997), 147-164.

Forestal, Eileen (2005a). "The Emerging Professionals: Deaf Interpreters and Their Views and Experiences on Training”. M. Marschark, R. Peterson and E.A. Winston (eds). Sign Language Interpreting and Interpreter Education: Directions for Research and Practice. Oxford: Oxford University Press, 235-258.

Forestal, Eileen (2005b). "Attitudes of Deaf Leaders Toward Signed Language Interpreters and Interpreting". Metzger \& Fleetwood (2005), 71-91.

Fowler, Yvonne (2003). "Taking an Interpreted Witness Statement at the Police Station: What Did the Witness Actually Say?”. L. Brunette, G. Bastin, I. Hemlin and H. Clarke (eds) (2003). The Critical Link 3. Interpreters in the Community. Selected papers from the Third International Conference on Interpreting in Legal, Health and Social Service Settings, Montréal, Quebec, Canada 22-26 May 2001. Benjamins Translation Library 26. Amsterdam/Philadelphia: John Benjamins, 195-209.

Frishberg, Nancy (1990). Interpreting: An Introduction. Revised edition. Silver Spring, MD: RID Publications.

Gentile, Adolfo (1997). “Community Interpreting or Not? Practices, Standards and Accreditation”. Carr et al. (1997), 109-118.

Gentile, Adolfo, Uldis Ozolins and Mary Vasilakakos (1996). Liaison Interpreting. A Handbook. Carlton South, Victoria: Melbourne University Press.

Gile, Daniel (1998). "Observational Studies and Experimental Studies in the Investigation of Conference Interpreting". Target 10(1), 69-93.

Gile, Daniel (2004). "Translation Research versus Interpreting Research: Kinship, Differences and Prospects for Partnership”. C. Schäffner (ed.). Translation Research and Interpreting Research. Traditions, Gaps and Synergies. Clevedon/Buffalo/Toronto: Multilingual Matters, 10-34.

Grbić, Nadja (2006). "From 10-minute wedding ceremonies to three-week spa treatment programs. Reconstructing the system of sign language interpreting in Styria”. A. Pym, Z. Jettmarová \& M. Shlesinger (eds). Sociocultural Aspects of Translating and Interpreting. Amsterdam/ Philadelphia: John Benjamins, 205-218.

Grünberg, Martin (1998). “Verhandlungsdolmetschen”. Snell-Hornby et al. (1998), 316-319.

Hansen, Gyde (2005). "Combination and Triangulation of Methods and Data". On line at http://www.est-translationstudies.org.

Humphrey, Janice H. \& Bob J. Alcorn (1995). So You Want To Be An Interpreter: An Introduction To Sign Language Interpreting. Second Edition. Amarillo, Texas: H \& H Publishers.

Inghilleri, Moira (2003). "Habitus, field and discourse. Interpreting as a socially situated activity". Target 15(2), 243-268.

Ingram, Robert M. (1978). "Sign Language Interpretation and General Theories of Language, Interpretation and Communication". D. Gerver \& H.W. Sinaiko (eds). Language Interpretation and Communication. New York/London: Plenum Press, 109-118.

Janzen, Terry (ed.) (2005). Topics in Signed Language Interpreting: Theory and Practice, Amsterdam/Philadelphia: John Benjamins.

Kellet Bidoli, Cynthia Jane (2002). "Spoken language and signed-language interpretation: are they really so different?" G. Garzone \& M. Viezzi (eds). Interpreting in the $21^{\text {st }}$ Century: Challenges and Opportunities. Benjamins Translation Library 43. Amsterdam/Philadelphia: John Benjamins, 171-179. 
Kurz, Ingrid (1998). “Mediendolmetschen”. Snell-Hornby et al. (1998), 311-312.

Madden, Maree (2005). "The Prevalence of Occupational Overuse Syndrome in Signed Language Interpreters in Australia - What a Pain!". Metzger \& Fleetwood (2005), 3-70.

Mason, Ian (1999). "Introduction". The Translator 5(2), 147-160.

Mesa, Anne-Marie (2000). "The Cultural Interpreter: An Appreciated Professional. Results of a Study on Interpreting Services: Client, Health Care Worker and Interpreter Points of View". R. P. Roberts, S.E. Carr, D. Abraham, \& A. Dufour (eds). The Critical Link 2: Interpreters in the community. Selected papers from the Second International Conference on Interpreting in Legal, Health and Social Service Settings, Vancouver, BC, Canada, 19-23 May 1998. Benjamins Translation Library 31. Amsterdam/Philadelphia: John Benjamins, 67-79.

Metzger, Melanie (1999). Sign Language Interpreting: Deconstructing the Myth of Neutrality. Washington, DC: Gallaudet University Press.

Metzger, Melanie \& Earl Fleetwood (eds) (2005). Attitudes, Innuendo, and Regulators: Challenges of Interpretation. Washington, DC: Gallaudet University Press.

Meyer, Bernd (2004). Dolmetschen im medizinischen Aufklärungsgespräch. Münster: Waxmann.

Napier, Jemina (2002). Sign language interpreting: Linguistic coping strategies. Coleford: Douglas McLean.

Neumann Solow, Sharon (1981). Sign Language Interpreting. A Basic Resource Book. Silver Spring, MD: The National Association of the Deaf.

Ozolins, Uldis \& Marianne Bridge (1999). Sign Language Interpreting in Australia. Melbourne: Language Australia.

Pöchhacker, Franz \& Miriam Shlesinger (eds) (2002). The Interpreting Studies Reader. London/New York: Routledge.

Pöchhacker, Franz (1998a) "Simultandolmetschen". Snell-Hornby et al., 301-304.

Pöchhacker, Franz (1998b). "Unity in Diversity. The Case of Interpreting Studies". L. Bowker, M. Cronin, D. Kenny, \& J. Pearson (eds). Unity in Diversity? Current Trends in Translation Studies. Manchester: St. Jerome, 169-176.

Pöchhacker, Franz (2000). Dolmetschen. Konzeptuelle Grundlagen und deskriptive Untersuchungen. Tübingen: Stauffenburg.

Pöchhacker, Franz (2004). Introducing Interpreting Studies. London/New York: Routledge.

Pöllabauer, Sonja (2005). "I don't understand your English, Miss". Dolmetschen bei Asylanhörungen. Tübingen: Gunter Narr.

Roberts, P. Roda (1987). "Spoken language interpreting versus sign language interpreting”. K. Kummer (ed.). Proceedings of the $28^{\text {th }}$ annual conference of the American Translators Association. Medford, NJ: Learned Information, 293-307.

Roberts, P. Roda (1997). "Community Interpreting Today and Tomorrow". Carr et al. (1997), 7-26.

Roy, Cynthia B. (2000). Interpreting as a Discourse Process. Oxford: Oxford University Press.

Russell, Debra (2005). “Consecutive and Simultaneous Interpreting”. Janzen (2005), 135-164.

Sanheim, Laura M. (2003). "Turn Exchange in an Interpreted Medical Encounter". M. Metzger, S. Collins, V. Dively \& R. Shaw (eds). From Topic Boundaries to Omission. New Research on Interpretation. Washington, DC: Gallaudet University Press, 27-54.

Seal, Brenda C. (2004). "Psychological Testing of Sign Language Interpreters". Journal of Deaf Studies and Deaf Education 9(1), 39-52.

Shaw, Sherry, Nadja Grbić \& Kathy Franklin (2004). "Applying language skills to interpretation: Student perspectives from signed and spoken language programs". Interpreting 6(1), 69100.

Shuttleworth, Mark \& Moira Cowie (1997). Dictionary of Translation Studies. Manchester: St. Jerome.

Snell-Hornby, Mary, Hans G. Hönig, Paul Kußmaul \& Peter A. Schmitt (eds) (1998). Handbuch Translation. Tübingen: Stauffenburg.

Swabey, Laurie (1992). "Interpreting in community settings: A comparison of sign language and spoken language interpreters". J. Plant-Moeller (ed.) (1992) Expanding Horizons. Proceedings of the Twelfth National Convention of the Registry of Interpreters for the Deaf. August 6-11, 1991. Silver Spring, MD: RID Publications, 106-119.

Tate, Granville, Judith Collins \& Peter B. Tymms (2003). "Assessments using BSL: Issues of translation for performance indicators in primary schools". Deaf Worlds 19(1), 6-35.

Turner, Graham H. \& Kyra Pollitt (2002). "Community Interpreting Meets Literary Translation. English-BSL Interpreting in the Theatre". The Translator 8(1), 25-48.

Wadensjö, Cecilia (1992). Interpreting as Interaction: On Dialogue Interpreting in Immigration Hearings and Medical Encounters. Linköping Studies in Arts and Science 83. PhD thesis. Linköping University.

Wadensjö, Cecilia (1998a). “Community Interpreting”. Baker (1998), 33-37. 
Wadensjö, Cecilia (1998b). Interpreting as Interaction. Language in Social Life Series. London, New York: Longman.

The German terms are the "forms of interpreting" mentioned in the Handbuch Translation.

2 The Routledge Encyclopedia of Translation Studies features one joint article on "Conference and simultaneous interpreting".

3 Alexieva (1997) also refers to Salevsky, who distinguished between different varieties of interpreting (based on a distinction between the consecutive and simultaneous mode - for references cf. Alexieva 1997).

4 The bibliography quotes the revised edition (1990).

5 Conferences (and conference series) that focus mainly on CI, like the Critical Link Conference Series $(1995,1998,2001,2004)$ or the series of conferences on CI hosted by the University of Alcalá de Henares $(2002,2005)$, may also serve to prove that CI has gradually become accepted in IR. Both of the series mentioned here invite participants to contribute papers on spoken and signed language interpreting.

Only a few authors have focused, more or less comprehensively, on the differences (and similarities) between spoken and signed language interpreting (cf. e.g. Roberts 1987; Swabey 1992; Kellet Bidoli 2002; Napier 2002: 29ff.).

7 Translation of written texts into SL on video, such as educational resources, children's books, websites, diagnostic tests, assessments, etc.

8 In order to establish exactly (and assess quantitatively) whether corpus-based discourse-analytical or survey-based (or other) studies predominate in CI research, it would be necessary to analyse a comprehensive body of work. 